\title{
Tissue and serum lipidome shows altered lipid composition with diagnostic potential in mycosis fungoides
}

\author{
Chenchen $X u^{1, *}$, Dan Zhou ${ }^{2, *}$, Yixin Luo ${ }^{1}$, Shuai Guo ${ }^{2}$, Tao Wang ${ }^{1}$, Jie Liu ${ }^{1}$, Yuehua \\ Liu $^{1}$ and Zhili Li ${ }^{2}$ \\ ${ }^{1}$ Department of Dermatology, Peking Union Medical College Hospital, Chinese Academy of Medical Sciences and Peking Union \\ Medical College, Beijing 100730, China \\ ${ }^{2}$ Department of Biophysics and Structural Biology, Institute of Basic Medical Sciences, Chinese Academy of Medical Sciences \\ and Peking Union Medical College, Beijing 100005, China \\ "These authors have contributed equally to this work and should be considered co-first authors \\ Correspondence to: Jie Liv, email: Liujie04672@pumch.cn \\ Yuehua Liv, email: yuehualiv@263.net \\ Zhili Li, email: lizhili@ibms.pumc.edu.cn
}

Keywords: cutaneous T cell lymphoma, mycosis fungoides, mass spectrometry imaging, matrix-assisted laser desorption/ionizationFourier transform ion cyclotron resonance mass spectrometry, lipidomics

Received: December 23, $2016 \quad$ Accepted: May 04, $2017 \quad$ Published: May 26, 2017

Copyright: Xu et al. This is an open-access article distributed under the terms of the Creative Commons Attribution License 3.0 (CC BY 3.0), which permits unrestricted use, distribution, and reproduction in any medium, provided the original author and source are credited.

\section{ABSTRACT}

Mycosis fungoides (MF) is the most common type of cutaneous T cell lymphoma. In this study, we used matrix-assisted laser desorption/ionization-Fourier transform ion cyclotron resonance mass spectrometry (MALDI-FTICR-MS) to perform lipidomic profiling of 5 MF tissue samples and 44 serum samples ( 22 from MF patients and 22 from control subjects). Multivariate statistical analysis of the mass spectral data showed that MF tissues had altered levels of seven lipids and MF sera had altered levels of twelve. Among these, six phosphotidylcholines, PC (34:2), PC (34:1), PC (36:3), PC (36:2), PC (32:0), and PC (38:4) and one sphingomyelin, SM (16:0) were altered in both MF tissues and sera. PC (34:2), PC (34:1), PC (36:3), and PC (36:2) levels were increased in both tissues and sera from MF patients, whereas SM (16:0), PC (32:0), and PC (38:4) levels were increased in MF sera but were decreased in MF tissues. We have thus identified multiple lipids that are altered in MF tissues and sera. This suggests serological and tissue lipidomic profiling could be an effective approach to screening for diagnostic biomarkers of MF.

\section{INTRODUCTION}

Mycosis fungoides (MF) is the most common type of cutaneous T cell lymphoma (CTCL) [1]. It is often misdiagnosed as inflammatory skin disease because of scaly erythematous patches and plaques that are presented for years. However, the advanced form of MF is presented as generalized tumors involving the lymph nodes and inner viscera [2]. There is no effective treatment for advanced stage MF and the median survival time is less than 1.5 years. Therefore, new MF diagnostic biomarkers are necessary for early detection and clinical intervention to improve outcomes [3]. But, the etiology of MF is poorly understood. Aberrant expression and function of the many transcriptional factors and regulators of signal transduction has been reported in CTCL [4]. In most cases, the oncogenes activate downstream targets that are either directly or indirectly connected to the metabolism [5].

Lipidomics is an important branch of metabolomics used to profile lipid content and composition [6]. Lipid metabolism is closely associated with cell growth, proliferation, differentiation, and motility [7]. Therefore, lipidomal profile changes are generally associated with cancer, metabolic diseases, neurological diseases and inflammation. It is plausible that MF also involves changes in lipid metabolism that can be identified by lipidomics. Therefore, we postulated that lipidomic profiling may help identify lipid diagnostic biomarkers of CTCL. We opted for 
matrix-assisted laser desorption/ionization-mass spectrometry imaging (MALDI-MSI) that simultaneously maps multiple lipids while preserving the morphological integrity of the analyzed tissue [8]. MALDI coupled with Fourier transform ion cyclotron resonance mass spectrometry (FTICR-MS) has high resolution and mass accuracy that can greatly improve its reliability and validity [9].

Therefore, the aim of this study was to elucidate the expression profile of lipids in MF by MALDI-FTICRMS imaging and identify potential tissue and serum biomarkers in MF.

\section{RESULTS}

\section{Mass spectral imaging of MF tissue samples}

We used mass spectrometry imaging (MSI) in the positive ion mode to analyze the intensities of various phosphatidylcholines (PCs) and sphingomyelins (SMs) in the cancer and adjacent non-cancer areas in MF patient tissue sections. The ion intensities of PC (34:2) at $\mathrm{m} / \mathrm{z}$ 796.5253, PC (34:1) at $\mathrm{m} / z$ 798.5410, PC (36:3) at $\mathrm{m} / \mathrm{z}$ 822.5410, and PC $(36: 2)$ at $m / z 824.5566$ were higher in the cancer areas compared to the adjacent non-cancer areas (Figure 1). Also, the ion intensities of SM (16:0) at $m / z$ 725.5568, PC (32:0) at $m / z 772.5253$, and PC (38:4) at $m / z 848.5566$ were lower in the tumor areas compared to the adjacent non-tumor areas (Figure 1). The images of H\&E and CD4 immunohistochemical stained tissue sections are shown in Figure 2.

\section{Differentially expressed lipids in cancer areas of MF tissue samples}

To further confirm the lipid changes in MF, we collected twenty spectra (or pixels) at different positions of both MF cancer and non-cancer areas for each tissue sample. Then, we conducted multivariate statistical analysis of 138 lipids (or variables) to assess MF tissue heterogenity. The PLS-DA score plots showed differences between cancer (blue dots) and the adjacent non-cancer (red dots) areas with the predicted residual sum of square (PRESS) of 0.3350 (Figure 3A). These results demonstrated changes in lipid profile between the normal and MF cancer tissues. The differentially expressed lipids with VIP values of more than 1.0 were identified (Figure 3B). As shown in Table 1, the 7 differentially expressed lipids are SM (16:0), PC (32:0), PC (34:2), PC (34:1), PC (36:3), PC (36:2) and PC (38:4).

\section{Differentially expressed lipids in MF patient sera}

MALDI-FTICR MS analysis was conducted on serum samples from $22 \mathrm{MF}$ and control subjects each. Then, multivariate analysis was performed for 130 lipids based on the mass spectrometry data. The PLS-DA score

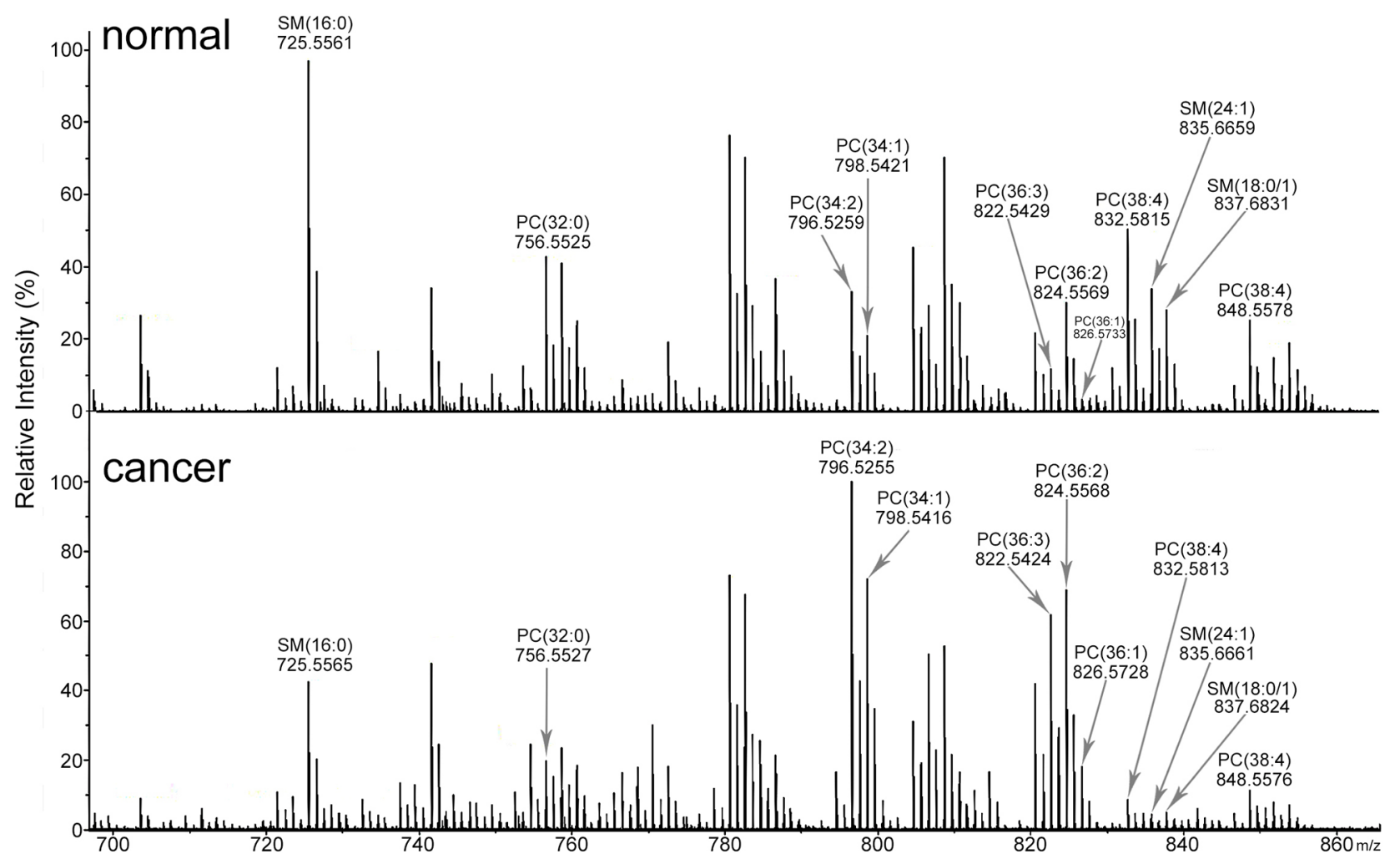

Figure 1: Mass spectra of lipids in MF tissue sections. Representative mass spectra of MF tissue sections in positive ion mode showing differences in lipid composition between cancer (bottom) and adjacent non-cancer (top) areas. 
CD4 immuno-
histochemical
staining

H\&E

staining

$\mathrm{H} \& \mathrm{E}$
staining

SM(16:0)

$\mathrm{m} / \mathrm{z} 725.5568$
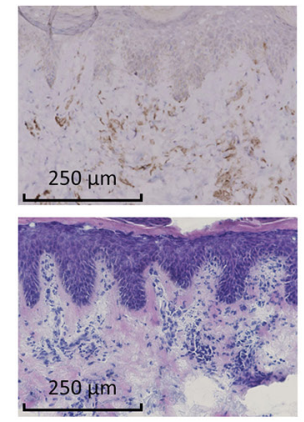

$2.5 \mathrm{~mm}$

$\mathrm{PC}(32: 0)$

$m / z 772.5253$

PC(38:4)

$\mathrm{m} / \mathrm{z} 848.5566$

PC(34:2)

$\mathrm{m} / \mathrm{z} 796.5253$

$\mathrm{PC}(34: 1)$

$\mathrm{m} / \mathrm{z} 798.5410$

$\mathrm{PC}(36: 3)$

$m / z 822.5410$

PC(36:2)

$\mathrm{m} / \mathrm{z} 824.5566$
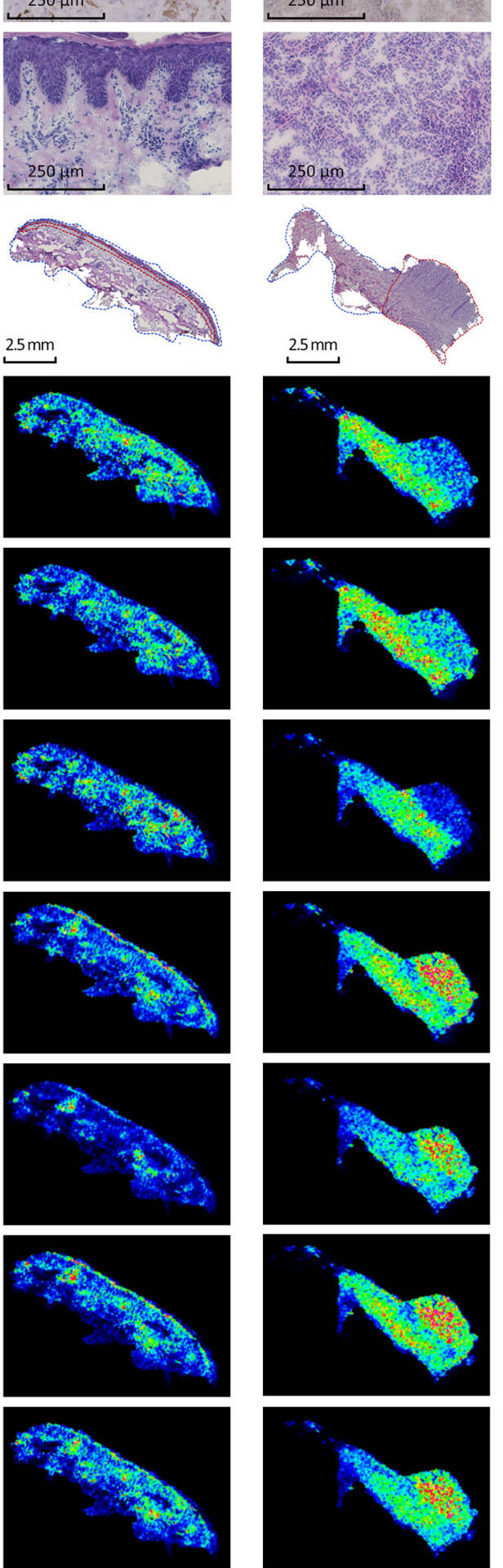
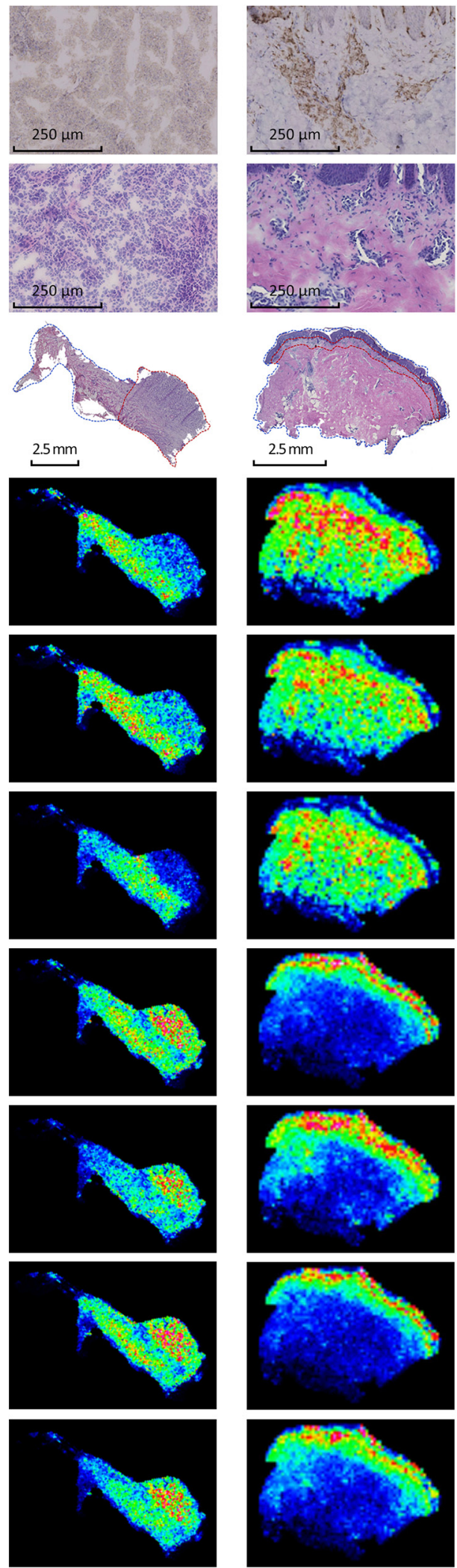
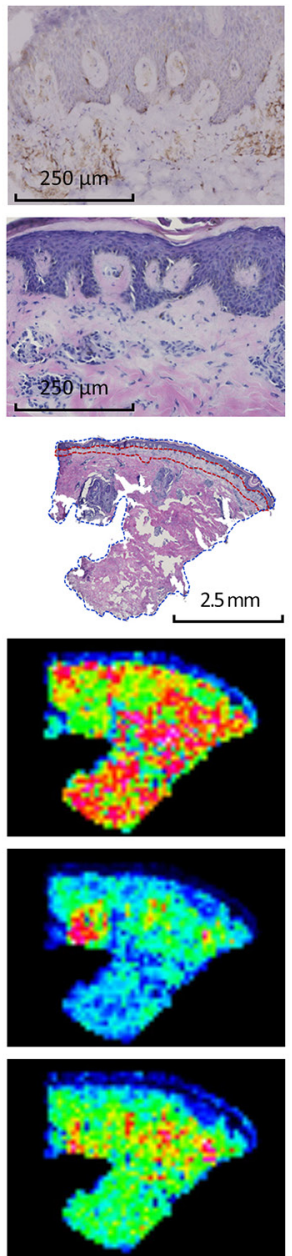

$0 \%$
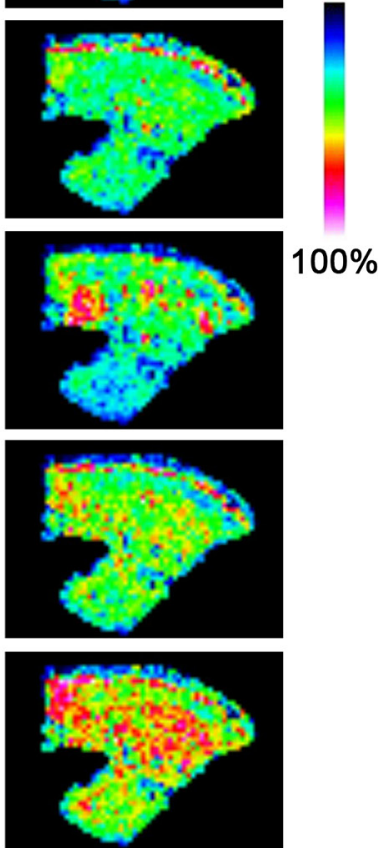

Figure 2: Mass spectrometry imaging of MF tissues. Representative mass spectrometry images of 4 MF tissue samples $(1,34$ and 5; left to right) showing ions SM (16:0) at m/z 725.5568, PC (32:0) at $\mathrm{m} / \mathrm{z} 772.5253, \mathrm{PC}(38: 4)$ at $\mathrm{m} / \mathrm{z} 848.5566, \mathrm{PC}(34: 2)$ at $\mathrm{m} / \mathrm{z}$ 796.5253, PC (34:1) at $\mathrm{m} / \mathrm{z} 798.5410, \mathrm{PC}(36: 3)$ at $\mathrm{m} / \mathrm{z} 822.5410$, and PC (36:2) at $\mathrm{m} / \mathrm{z} 824.5566$. The corresponding H\&E and CD4 immunohistochemical staining is shown on top. The areas corresponding to cancer and adjacent non-cancer areas are shown by red and blue dotted lines, respectively. Note: The cell types in the non-cancer areas include keratinocytes, fibroblasts, fibers and matrix. 
Table 1: Indentified important lipids from tissues and sera

\begin{tabular}{|c|c|c|c|c|c|c|}
\hline $\begin{array}{l}\text { Measured, } \\
m / z\end{array}$ & $\begin{array}{l}\text { Calculated, } \\
\qquad m / z\end{array}$ & $\begin{array}{l}\text { Error } \\
(\mathrm{ppm})\end{array}$ & Ion form & Compound & $\begin{array}{l}\text { Molecular } \\
\text { formula }\end{array}$ & $\begin{array}{l}\text { Structurally specific CID ions, } \\
\mathrm{m} / \mathrm{z}\end{array}$ \\
\hline 482.3607 & 482.3605 & 0.39 & {$[\mathrm{M}+\mathrm{H}]^{+}$} & $\begin{array}{c}\mathrm{PC}(\mathrm{O}- \\
16: 0 / 0: 0)\end{array}$ & C24H52NO6P & \\
\hline 496.3401 & 496.3398 & 0.56 & {$[\mathrm{M}+\mathrm{H}]^{+}$} & LPC $(16: 0)$ & C24H50NO7P & \\
\hline 510.3556 & 510.3554 & 0.31 & {$[\mathrm{M}+\mathrm{H}]^{+}$} & $\operatorname{LPE}(20: 0)$ & C25H52NO7P & \\
\hline 520.3399 & 520.3398 & 0.17 & {$[\mathrm{M}+\mathrm{H}]^{+}$} & $\operatorname{LPC}(18: 2)$ & C26H50NO7P & \\
\hline 524.3711 & 524.3711 & 0.11 & {$[\mathrm{M}+\mathrm{H}]^{+}$} & LPC(18:0) & C26H54NO7P & \\
\hline 758.5691 & 758.5694 & -0.41 & {$[\mathrm{M}+\mathrm{H}]^{+}$} & $\mathrm{PC}(34: 2)$ & C42H80NO8P & \\
\hline 796.5252 & 796.5253 & -0.18 & {$[\mathrm{M}+\mathrm{K}]^{+}$} & $\mathrm{PC}(34: 2)$ & C42H80NO8P & $613.4600 / 737.4512 / 796.5252$ \\
\hline 798.5409 & 798.5410 & -0.14 & {$[\mathrm{M}+\mathrm{K}]^{+}$} & $\mathrm{PC}(34: 1)$ & $\mathrm{C} 42 \mathrm{H} 82 \mathrm{NO} 8 \mathrm{P}$ & $615.4752 / 739.4690 / 798.5409$ \\
\hline 824.5564 & 824.5566 & -0.22 & {$[\mathrm{M}+\mathrm{K}]^{+}$} & $\operatorname{PC}(36: 2)$ & C44H84NO8P & $641.4915 / 765.4838 / 824.5566$ \\
\hline 725.5566 & 725.5568 & -0.32 & {$[\mathrm{M}+\mathrm{Na}]^{+}$} & $\operatorname{SM}(16: 0)$ & C39H79N2O6P & $542.4914 / 666.4845 / 725.5568$ \\
\hline 756.5509 & 756.5514 & -0.58 & {$[\mathrm{M}+\mathrm{Na}]^{+}$} & $\operatorname{PC}(32: 0)$ & C40H80NO8P & $573.4856 / 697.4774 / 756.5514$ \\
\hline 772.5254 & 772.52532 & 0.16 & {$[\mathrm{M}+\mathrm{K}]^{+}$} & $\mathrm{PC}(32: 0)$ & C40H80NO8P & \\
\hline 822.5408 & 822.5410 & -0.21 & {$[\mathrm{M}+\mathrm{K}]^{+}$} & $\operatorname{PC}(36: 3)$ & C44H82NO8P & $639.4770 / 763.4685 / 822.5409$ \\
\hline 832.5820 & 832.5827 & -0.86 & {$[\mathrm{M}+\mathrm{Na}]^{+}$} & $\operatorname{PC}(38: 4)$ & C46H84NO8P & $649.5164 / 773.5077 / 832.5826$ \\
\hline 848.5564 & 848.5566 & -0.21 & {$[\mathrm{M}+\mathrm{K}]^{+}$} & $\mathrm{PC}(38: 4)$ & C46H84NO8P & \\
\hline
\end{tabular}

plots showed two clusters between MF (blue dots) and the control samples (red dots) with predicted residual sum of square (PRESS) score of 0.3775 (Figure 4A). This suggested changes in serum lipid profiles of MF patients. We identified 12 lipids with VIP values of more than 1.0 (Figure 4B). As shown in Table 1, these included lysophosphatidylcholines (LPCs) [LPC(16:0), LPC(18:0), LPC(18:2)], lysophosphatidylethanolamines (LPEs)

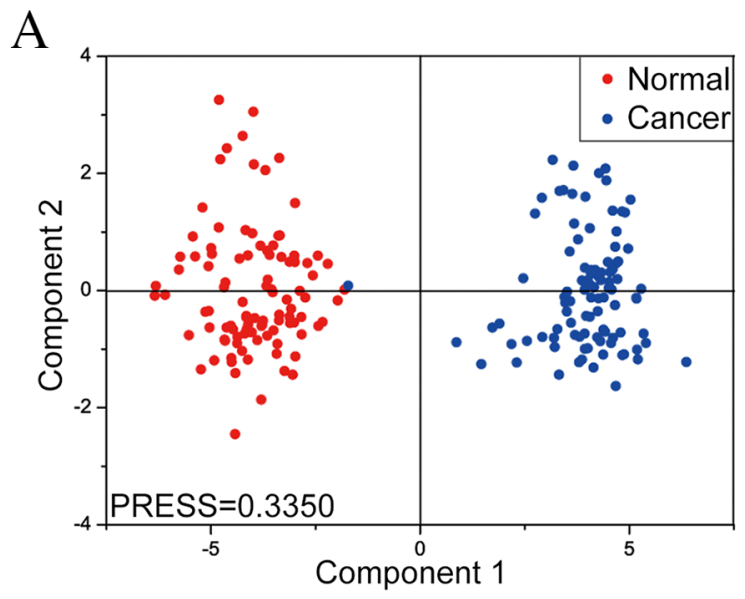

[LPE(20:0)], $\quad \mathrm{PC}(34: 2), \quad \mathrm{PC}(\mathrm{O}-16: 0 / 0: 0), \quad \mathrm{PC}(36: 2)$, $\mathrm{PC}(32: 0), \mathrm{PC}(36: 3), \mathrm{PC}(38: 4), \mathrm{PC}(34: 1)$ and $\mathrm{SM}(16: 0)$.

\section{Identification of potential lipid diagnostic biomarkers in MF tissues and sera}

In tissues, we observed low levels of SM (16:0), PC (32:0), PC (38:4) and high levels of PC (34:2), PC (34:1),

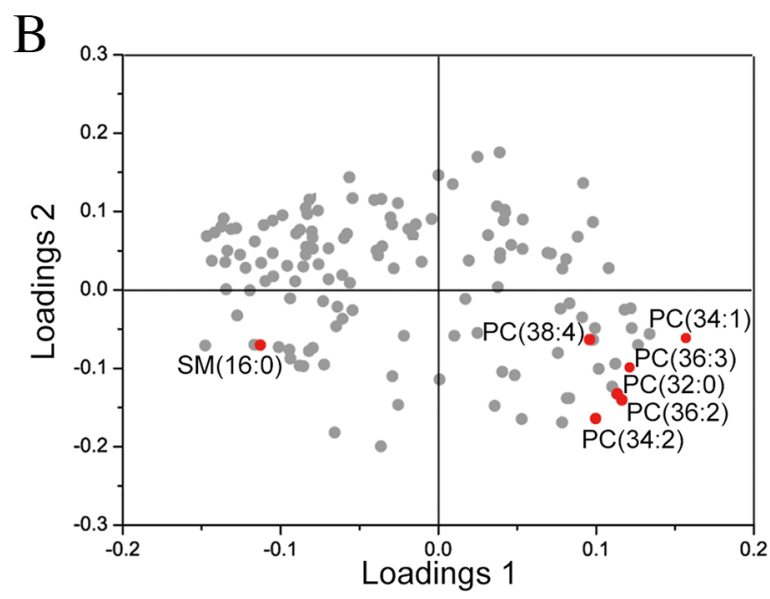

Figure 3: Partial least squares-discriminant analysis of lipid profiles in cancer and non-cancer areas of MF tissues. (Left) Partial least squares-discriminant analysis (PLS-DA) score plot of component 2 versus component 1 for cancer (blue dots) and adjacent non-cancer (red dots) areas from MF patient tissue samples. (Right) PLS-DA loading plot comparing variables (lipids) between cancer (loadings 1) and non-cancer areas (loadings 2) in MF patient tissue sections. The variables (lipids) in tissue samples with VIP values of more than 1.0 are marked in red. 
PC (36:3) and PC (36:2) in MF cancer areas compared to adjacent non-cancer areas (Figure 5). On the other hand, we observed low levels of PC (O-16:0/0:0), LPC (16:0), LPC (18:0) and LPE (20:0) and high levels of PC (34:2), LPC (18:2), PC (36:2), PC (32:0), SM (16:0), PC (36:3), PC (38:4), PC (34:1) in MF patients compared to control subjects (Figure 6).

We observed that PC (34:2), PC (34:1), PC (36:3), PC (36:2), SM (16:0), PC (32:0), and PC (38:4) changed in both tissues and sera of MF patients compared to control subjects. Interestingly, PC (34:2), PC (34:1), PC (36:3), and $\mathrm{PC}(36: 2)$ increased in both tissues and sera of MF patients, whereas SM (16:0), PC (32:0), and PC (38:4) levels increased in the sera but decreased in the tissues of MF patients compared to control subjects.

\section{DISCUSSION}

Mycosis fungoides accounts for $70-75 \%$ of all CTCLs. Patients with advanced MF have generalized tumors and a median survival of less than 1.5 years. Therefore, early diagnosis is of paramount importance.

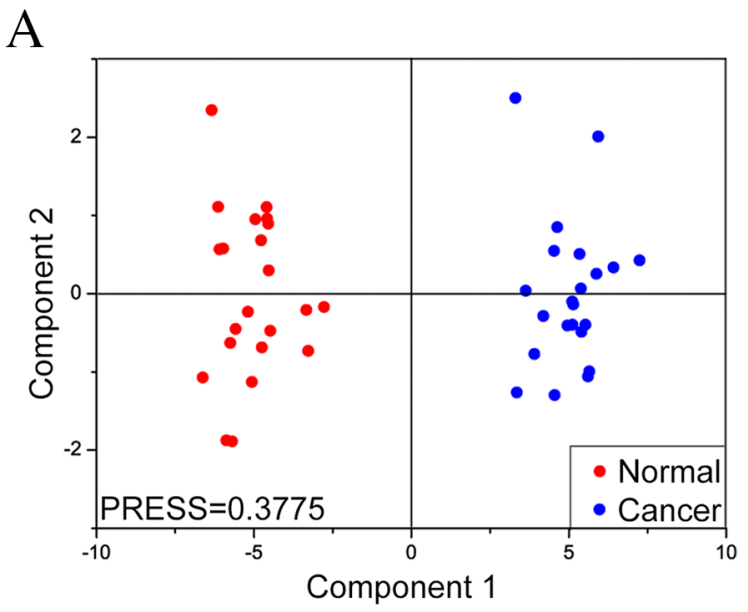

However, early diagnosis of MF is difficult due to nonspecific clinical manifestation and lack of effective diagnostic biomarkers [3]. Therefore, we investigated lipid profile changes in the $5 \mathrm{MF}$ tumor tissue samples and sera from $22 \mathrm{MF}$ and 22 control subjects by highly reliable and sensitive MALDI-FTICR-MS technique. We identified 12 differentially expressed lipids in the MF tissues and 7 differentially expressed lipids in the MF patient sera. We also compared the differentially expressed lipids in the tissues and sera of MF patients and identified a subset of lipids that are potential diagnostic biomarkers.

Lipidomics was first conducted in 2003 to analyze lipid profiles in experimental samples [10]. There are nine categories of lipids including fatty acids, glycerolipids, sphingolipids, glycerophospholipids, sterol lipids, prenolipids, saccharolipids, polyketides and sterols. Lipids are involved in many physiological metabolic pathways such as cell fusion/division, apoptosis, shape, membrane vesicle trafficking and signal transduction [11]. Altered lipid content is associated with many human diseases including diabetes, neurodegenerative diseases, heart disease and cancer [11]. It is well established

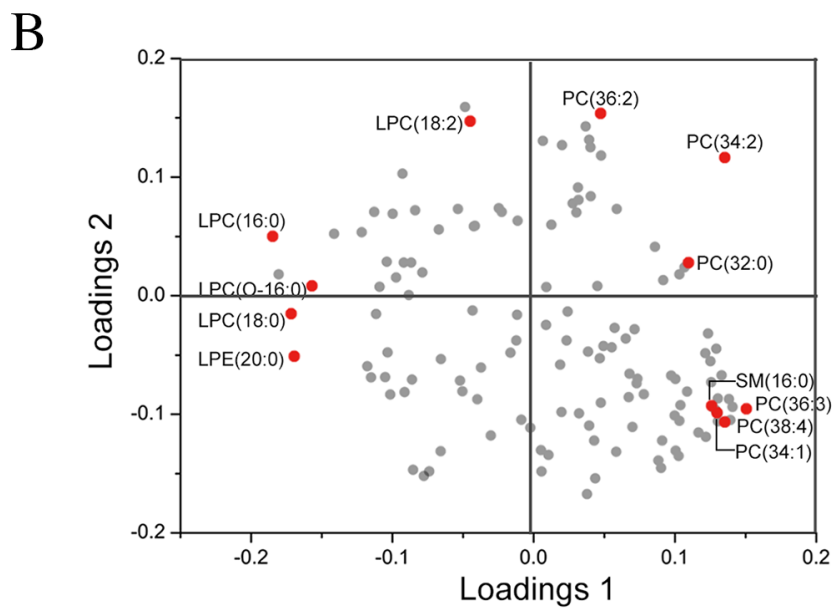

Figure 4: Partial least squares-discriminant analysis of lipid profiles of sera from MF and control subjects. (Left) PLSDA score plot of component 2 versus component 1 for serum samples from MF (blue dots) and control (red dots) subjects. (Right) PLS-DA loading plot comparing variables (lipids) between serum samples of MF and control subjects. The variables (lipids) in sera with VIP values of more than 1.0 are marked in red.

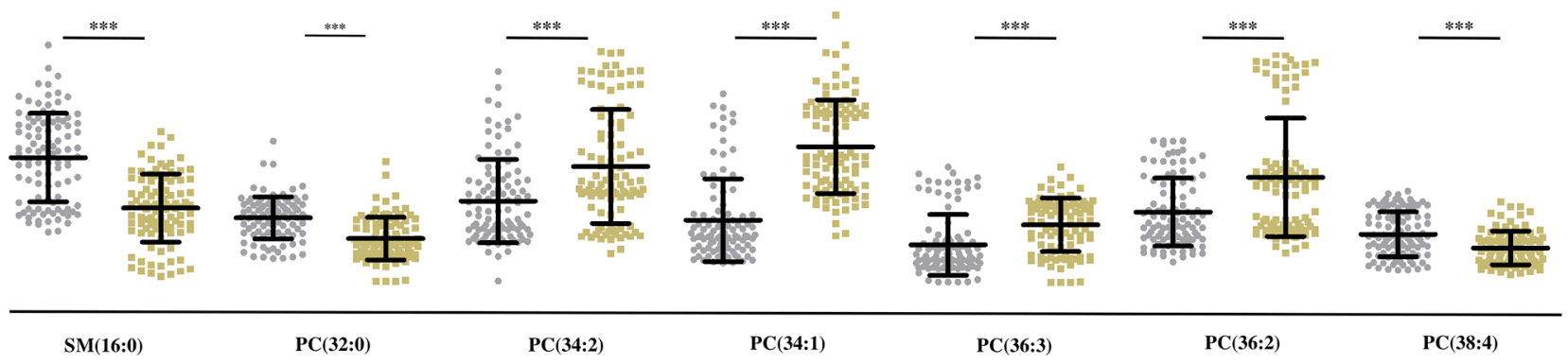

Figure 5: Quantitative analysis of 7 lipids in MF tissue samples. Scatter plots show levels of 7 differentially expressed lipids in non-cancer (grey dots) and cancer (yellow dots) areas in MF patient tissues. *** denotes $\mathrm{p}<.001 ; * *$ denotes $\mathrm{p}<.01$ and $*$ denotes $\mathrm{p}<.05$. 
that tumor cells change metabolic profiles for growth, survival and differentiation [12]. Altered lipid profiles have been demonstrated in many cells and tissues $[13,14]$. Some lipids have shown potential as tumor biomarkers. For example, increased polyunsaturated fatty acids (PUFAs) are observed in apoptosing glioma cells and in dedifferentiated and pleomorphic liposacomas $[15,16]$. Furthermore, Zhou et al identified metabolic changes in the plasma of CTCL patients and mapped the potential biomarkers with ultrahigh performance liquid chromatography-quadrupole time-of-flight mass spectrometry (UHPLC-QTOF-MS) [17]. They observed that a few lipids like LysoPC (16:0), LPA (16:0/0:0) and LPA (0:0/16:0) were aberrantly expressed in CTCL plasma in positive and negative modes. However, systematic lipidomic study in MF had not been conducted previously. To our best knowledge, ours is the first study to analyze lipidomic changes in both MF tissue samples and sera.

Spectroscopic methods including mass spectrometry (MS) have been preferred to traditional histochemical stains in lipidomic investigations. This is because the common lipid stains are limited to few neutral lipids in tissues only [18]. Among the spectroscopy methods, MALDI-MSI is the preferred choice for in situ lipid research because it can be performed on a tissue section without destroying the tissue. MALDI-MSI can be used for molecular classification and histological diagnosis. In addition, it can predict prognosis, treatment response, or metastasis potential of cancers as well. MALDI-MSI has high spatial resolution and sensitivity, good salt tolerance and broad mass range. Since it can be performed without destroying the tissue sample, histological evaluation can be performed on the same tissue sample [19]. Tissue morphology is critical for MF tissue analysis because the malignant tumor cells co-exist with normal skin cells, immune cells, blood vessels, connective tissue and other micro-environmental factors. MALDI-MSI has been used to study brain, breast, lung, ovarian, prostate, and gastrointestinal cancers [20]. However, very few studies on MF tissue samples are based on MALDI-MSI. Hence, we used MALDI-MSI to investigate lipidomic changes in MF tissue and sera samples.

Another crucial aspects in our study was using adjacent non-cancer area as control. This reduced the potential confounding variations due to diet, skin type, age, sex, genetic background, metabolic status, and environmental influences. Serum lipid profiling was also performed by MALDI-FTICR-MS in our study. We predicted that lipids that changed significantly in both tumor tissues and sera were potential diagnostic biomarkers. We also compared the lipid profiles in MF tissues and sera to gain further insights regarding our findings.

Phosphatidylcholine (PC) is abundant in cell membranes and involved in key cellular signaling pathways [21]. Aberrant phospholipid metabolism is also established in many cancers. Increased phospholipid content is demonstrated in transformed cells and during tumor progression [21]. Increased PC was also shown in breast cancer tissue compared to adjacent normal breast
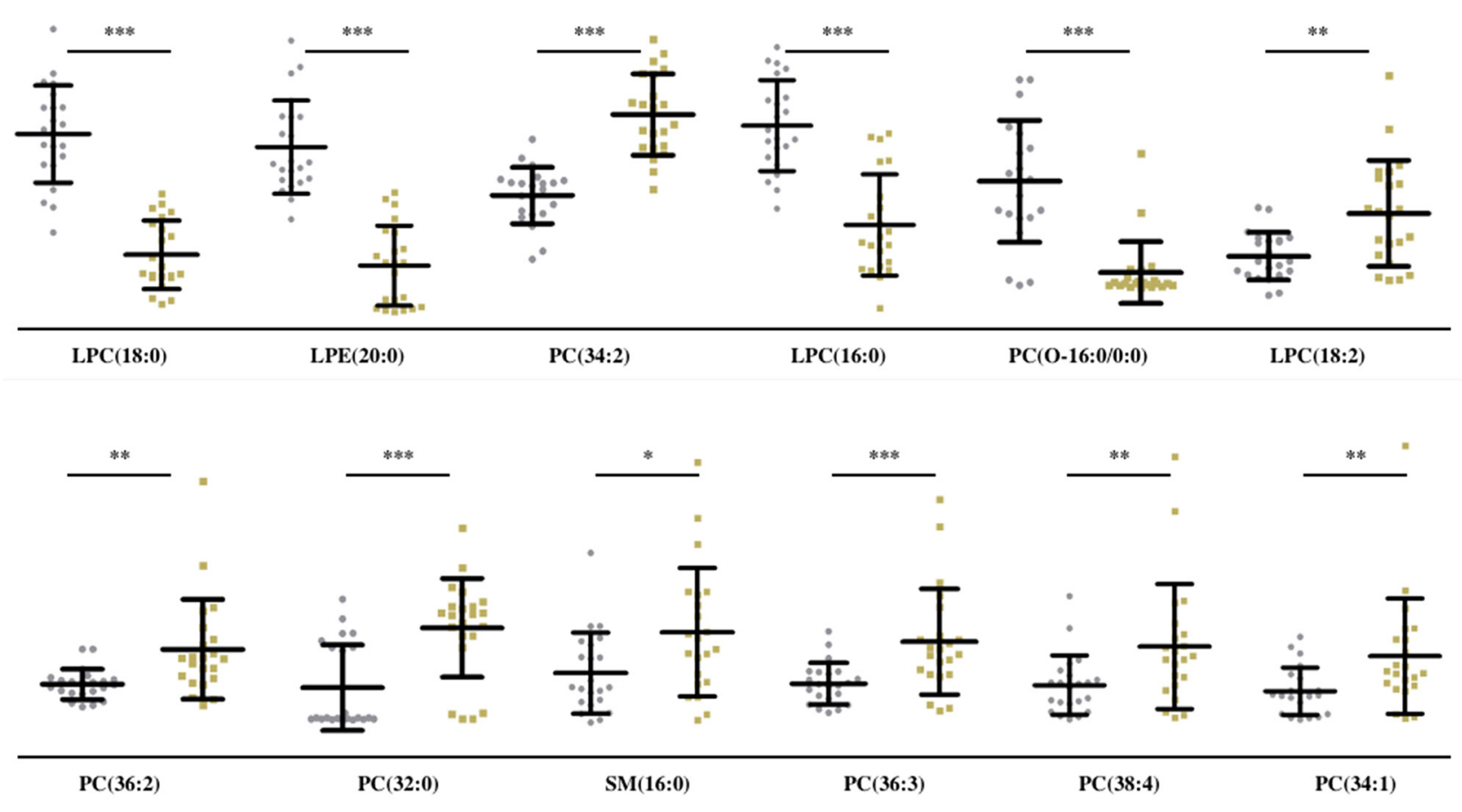

Figure 6: Quantitative analysis of 12 lipids in sera of MF and control subjects. Scatter plots show levels of 12 differentially expressed lipids in sera from control (grey dots) and MF (yellow dots) subjects. $* * *$ denotes $\mathrm{p}<.001 ; * *$ denotes $\mathrm{p}<.01$ and $*$ denotes $\mathrm{p}<.05$. 
Table 2: Clinical information of tissue and serum samples of MF patients

\begin{tabular}{|c|c|c|c|c|}
\hline Sample type & No. & Sex & Age & TNMB stage \\
\hline \multirow[t]{5}{*}{ Tissue } & 1 & $\mathrm{~F}$ & 70 & T3N0M0B0 \\
\hline & 2 & $\mathrm{~F}$ & 43 & T3N1M0B0 \\
\hline & 3 & $\mathrm{~F}$ & 35 & T2N0M0B0 \\
\hline & 4 & $\mathrm{~F}$ & 44 & T2N0M0B0 \\
\hline & 5 & M & 42 & T2N1M0B0 \\
\hline \multirow[t]{22}{*}{ Sera } & 1 & $\mathrm{~F}$ & 33 & T2N0M0B0 \\
\hline & 2 & M & 22 & T2N0M0B0 \\
\hline & 3 & M & 25 & T2N1M0B0 \\
\hline & 4 & $\mathrm{~F}$ & 55 & T2N1M0B0 \\
\hline & 5 & $\mathrm{~F}$ & 25 & T2N0M0B0 \\
\hline & 6 & M & 28 & T2N0M0B0 \\
\hline & 7 & M & 46 & T2N0M0B0 \\
\hline & 8 & $\mathrm{~F}$ & 67 & T2N0M0B0 \\
\hline & 9 & M & 49 & T2N0M0B0 \\
\hline & 10 & $\mathrm{~F}$ & 42 & T2N1M0B0 \\
\hline & 11 & $\mathrm{~F}$ & 70 & T3N0M0B0 \\
\hline & 12 & M & 19 & T2N0M0B0 \\
\hline & 13 & $\mathrm{~F}$ & 27 & T2N0M0B0 \\
\hline & 14 & M & 8 & T2N0M0B0 \\
\hline & 15 & $\mathrm{~F}$ & 43 & T3N0M0B0 \\
\hline & 16 & $\mathrm{~F}$ & 20 & T2N0M0B0 \\
\hline & 17 & M & 25 & T2N0M0B0 \\
\hline & 18 & M & 14 & T2N0M0B0 \\
\hline & 19 & $\mathrm{~F}$ & 34 & T3N0M0B0 \\
\hline & 20 & $\mathrm{~F}$ & 43 & T3N1M0B0 \\
\hline & 21 & M & 27 & T3N0M0B0 \\
\hline & 22 & $\mathrm{~F}$ & 30 & T4N1M0B0 \\
\hline
\end{tabular}

(Tissue No.1 and sera No.11 came from same patient. Tissue No.2 and sera No.20 came from same patient.)

Table 3: Clinical information of serum samples

\begin{tabular}{lccc}
\hline & No. & Sex (female/male) & Age (mean \pm SD) \\
\hline MF & 22 & $12 / 10$ & $34.18 \pm 16.12$ \\
Normal & 22 & $12 / 10$ & $35.64 \pm 15.44$ \\
\hline
\end{tabular}

tissue [22]. In our study, PC (34:2), PC (34:1), PC (36:3), and $\mathrm{PC}(36: 2)$ increased significantly between $\mathrm{MF}$ and normal tissue and sera. However, PC (32:0), and PC (38:4) decreased in $\mathrm{MF}$ tissue compared to adjacent non-tumor tissue.
Sphingomyelins (SMs) are lipids that regulate many cellular functions, since they transmit the transmembrane signals through microdomains and the intracellular vesicular trafficking [23]. Also, SMs modulate cancer cell death. Studies have shown that some SMs promote 
tumorigenesis, whereas others repress it [24]. In this study, we observed low levels of SM (16:0) in MF tissues. However, in the sera, we observed high levels of SM (16:0) in MF patients. The reason for these differences is not known and need to be further investigated.

In summary, we comprehensively analyzed the lipid profiles of MF patient tissues and sera by MALDI-FTICRMS. We found altered lipid composition in both tissue and sera of MF patients and identified few lipids with diagnostic potential. Our study also showed that serological lipidomic profiling combined with tissue MSI is a powerful tool for screening novel diagnostic biomarkers.

\section{MATERIALS AND METHODS}

\section{Patient recruitment and clinical sample collection}

This study was approved by the Ethics Committee of Institute of Peking Union Medical College Hospital, Chinese Academy of Medical Sciences. Informed consent was obtained from all participants. Tissue samples were obtained from $5 \mathrm{MF}$ patients from Peking Union Medical College Hospital (Beijing, China) after clinical, pathological, immunohistochemical and TCR gene rearrangement investigations were completed and confirmed. The tissue samples were snap-frozen in liquid nitrogen after washing with normal saline, and stored at $-80^{\circ} \mathrm{C}$ until further experimentation. Serum samples were collected from $22 \mathrm{MF}$ patients enrolled at Peking Union Medical College Hospital (Beijing, China) and 22 age and sex matched healthy volunteers as controls after clinical laboratory tests or routine physical examinations. The serum samples were stored at $4^{\circ} \mathrm{C}$ for $<12 \mathrm{~h}$ and then transferred to $\mathrm{a}-80^{\circ} \mathrm{C}$ freezer until further use. All the tissue and serum samples were obtained before clinical treatment. The patients were staged according to TNMB staging system and were evaluated and diagnosed by two trained dermatologists. The detailed information is listed in Tables 2 and 3.

\section{Patient tissue sample preparation for MALDI- FTICR-MS}

Three $12 \mu \mathrm{m}$ thick tissue sections were cut from snap-frozen patient tissue samples. Of these, 2 were affixed onto glass slides and stained with either hematoxylin and eosin (H\&E) or CD4 immunohistochemical staining to determine cancer and non-cancer areas in each $\mathrm{MF}$ patient samples. The third section was thawed and mounted on a glass slide coated with indium tin oxide (ITO). Then, the tissue sample was immersed in $200 \mu \mathrm{L}$ of 2,5-dihydroxybenzoic acid (2,5-DHB; Sigma-Aldrich) solution $(10 \mathrm{mg} / \mathrm{ml}$ in methanol/ water $(50 / 50, \mathrm{v} / \mathrm{v}))$ as matrix for efficient ionization and enhance sensitivity of MALDI-FTICR-MS as previously described [25].

\section{Serum sample preparation for MALDI-FTICR-MS}

The serum samples were processed by first precipitating the serum proteins by mixing $50 \mu \mathrm{L}$ of each serum sample with $950 \mu \mathrm{L}$ of methanol/acetonitrile $(3 / 2 \mathrm{ratio}, \mathrm{v} / \mathrm{v})$. The mixture was vortexed for $1 \mathrm{~min}$ and stored at $4^{\circ} \mathrm{C}$ overnight followed by centrifugation at $19000 \mathrm{~g}$ for $30 \mathrm{~min}$ to collect the supernatant. Then, $250 \mu \mathrm{L}$ dichloromethane and $100 \mu \mathrm{L}$ ultrapure water $(18.2 \mathrm{M} \Omega / \mathrm{cm})$ were added to $50 \mu \mathrm{L}$ of the supernatant in a glass vial and mixed by vortexing for $30 \mathrm{~s}$. The mixture was centrifuged at $1250 \mathrm{~g}$ for $6 \mathrm{~min}$. Then, $75 \mu \mathrm{L}$ of the supernatant was transferred into a new glass vial and air-dried at room temperature. The dried samples were stored at $-80^{\circ} \mathrm{C}$ until further use. For MALDI-MS analysis, the dried sample was redissolved by $150 \mu \mathrm{L}$ of $50 \%$ methanol in ultrapure water $(\mathrm{v} / \mathrm{v})$. Then, $0.2 \mu \mathrm{L}$ of the solution was spotted onto a MTP 384 polished steel plate (BrukerDaltonics, Billerica, MA, USA), air-dried at room temperature, and then layered with $0.2 \mu \mathrm{L}$ of $10 \mathrm{mg} / \mathrm{ml} 2,5-\mathrm{DHB}$ in methanol/ water/formic acid (50/50/0.1, v/v/v) solution.

\section{Mass spectrometry}

MSI or mass spectrometry profiling was performed in a 9.4 T Apex-ultra hybrid Qh-FTICR mass spectrometer (Bruker Daltonics, Billerica, MA, USA) equipped with a $355 \mathrm{~nm} \mathrm{Nd} /$ YAG Smartbeam laser $(200 \mathrm{~Hz}$ ). Mass spectra were acquired over the $\mathrm{m} / \mathrm{z}$ range of $600-1000$ with a mass resolution of 400,000 at $\mathrm{m} / z 400$ in positive ion mode. For tissue analysis, mass spectrum at each pixel was conducted with two full scans with 70 laser shots each. MSI experiments were performed with a spatial resolution of $200 \mu \mathrm{m}$. For serum analysis, ten spectra were obtained for each sample with 50 laser shots for each scan.

\section{MS data processing and statistical analysis}

MS images were visualized using the FlexImaging software (version 2.1, Bruker Daltonics) with relative ion intensities. Instrument calibration was performed against four references $(\mathrm{m} / \mathrm{z} 725.5568, \mathrm{~m} / \mathrm{z}$ 796.5253, $\mathrm{m} / \mathrm{z}$ 824.5566 , and $\mathrm{m} / z$ 832.5827). Mass spectral data for tissue imaging and serum lipid analysis was obtained from the Apex Control 3.0.0 software (Bruker Daltonics, Billerica, MA, USA). Peaks with signal-to-noise ratio of $>3$, relative intensity of $>0.1 \%$, and absolute intensity threshold of more than 10000 were selected as reliable variables with reliable isotope distribution of less than $2 \%$ relative standard deviation between the experimental and theoretical values using DataAnalysis 4.0 software (Bruker Daltonics). After isotopic deconvolution, these peaks were aligned within a mass tolerance window $( \pm 0.001 \mathrm{Da})$ as a single variable among different samples. The $[\mathrm{M}+\mathrm{H}]^{+}$, $[\mathrm{M}+\mathrm{Na}]^{+}$, and $[\mathrm{M}+\mathrm{K}]^{+}$ions were also combined as one variable. Missing values for some variables were replaced with the half the baseline strength in each spectrum. The 
intensities of all variables from one mass spectrum were normalized to a constant number of 1000 .

The resulting dataset was transferred to a Microsoft Excel file (Microsoft, Redmond, WA, USA) for statistical analysis. SAS software (version 9.2, SAS Institute Inc., USA) was used for partial least squares discriminant analysis (PLS-DA). The predicted residual sum of square (PRESS) of PLS-DA was used to evaluate the model. Variables with $\mathrm{p}$ value of less than 0.05 (Wilcoxon- MannWhitney test) and variable importance in projection (VIP) of more than 1.0 were considered statistically significant.

\section{Structure identification}

The lipids of interest in tissues and sera were identified using HMDB (http://www.hmdb.ca), and LIPID MAPS (http:// www.lipidmaps.org/tools/index.html) databases based on their molecular mass, isotope distribution, and collision-induced dissociation tandem mass spectral data. The mass error was $<2 \mathrm{ppm}$ and the relative intensity error of their isotopic peaks between experimental and theoretical values was $<2 \%$.

\section{Abbrevations}

MF: mycosis fungoides; CTCL: cutaneous T cell lymphoma; MALDI: matrix-assisted laser desorption/ ionization; FTICR: fourier transform ion cyclotron resonance; MSI: mass spectrometry imaging; MS: mass spectrometry; PC: phosphatidylcholine; SM: sphingomyelin; LPC: lysophosphatidylcholine; LPE: lysophosphatidylethanolamine; PUFA: polyunsaturated fatty acid; UHPLC-QTOF-MS: ultrahigh performance liquid chromatography-quadrupole time-of-flight mass spectrometry; H\&E: hematoxylin and eosin; ITO: indium tin oxide; 2,5-DHB: 2,5- dihydroxybenzoic acid; PLSDA: partial least squares discriminant analysis; PRESS: predicted residual sum of square; VIP: variable importance in the projection

\section{Author contributions}

D.Z., S.G. and CC.X. performed experiments; D.Z. and S.G. analyzed results and prepared figures; CC.X. and J.L. designed the research and wrote the paper; YH.L., T.W. and YX.L. contributed vital new reagents or analytical tools; J.L. and ZL.L. supervised the study.

\section{ACKNOWLEDGMENTS}

This work was supported by the Beijing Natural Science Foundation (grant no.7142136) and The Milstein Medical Asian American Partnership Foundation Research Project Award in Skin Disease.

\section{CONFLICTS OF INTEREST}

The authors declare no conflicts of interest.

\section{REFERENCES}

1. Olsen E, Vonderheid E, Pimpinelli N, Willemze R, Kim Y, Knobler R, Zackheim H, Duvic M, Estrach T, Lamberg S, Wood G, Dummer R, Ranki A, et al. Revisions to the staging and classification of mycosis fungoides and Sezary syndrome: a proposal of the International Society for Cutaneous Lymphomas (ISCL) and the cutaneous lymphoma task force of the European Organization of Research and Treatment of Cancer (EORTC). Blood. 2007; 110: 1713-1722.

2. Fink-Puches R, Zenahlik P, Bäck B, Smolle J, Kerl H, Cerroni L. Primary cutaneous lymphomas: applicability of current classification schemes (European Organization for Research and Treatment of Cancer, World Health Organization) based on clinicopathologic features observed in a large group of patients. Blood. 2002; 99: 800-805.

3. Prince HM, Whittaker S, Hoppe RT. How I treat mycosis fungoides and Sézary syndrome. Blood. 2009; 114: 4337-4353.

4. Yin P, Peter A, Franken H, Zhao X, Neukamm SS, Rosenbaum L, Lucio M, Zell A, Häring HU, Xu G, Lehmann R. Preanalytical aspects and sample quality assessment in metabolomics studies of human blood. Clin Chem. 2013; 59: 833-845.

5. Locasale JW, Cantley LC, Vander Heiden MG. Cancer's insatiable appetite. Nat Biotechnol. 2009; 27: 916.

6. Li L, Han J, Wang Z, Liu J, Wei J, Xiong S, Zhao Z. Mass spectrometry methodology in lipid analysis. Int J Mol Sci. 2014; 15: 10492-10507.

7. Santos CR, Schulze A. Lipid metabolism in cancer. FEBS J. 2012; 279: 2610-2623.

8. Seeley EH, Caprioli RM. MALDI imaging mass spectrometry of human tissue: method challenges and clinical perspectives. Trends Biotechnol. 2011; 29: 136-143.

9. Smith DF, Kiss A, Leach FE 3rd, Robinson EW, PašaTolić L, Heeren RM. High mass accuracy and high mass resolving power FT-ICR secondary ion mass spectrometry for biological tissue imaging. Anal Bioanal Chem. 2013; 405: 6069-6076.

10. Han X, Gross RW. Global analyses of cellular lipidomes directly from crude extracts of biological samples by ESI mass spectrometry a bridge to lipidomics. J Lipid Res. 2003; 44: 1071-1079.

11. Cimino J, Calligaris D, Far J, Debois D, Blacher S, Sounni NE, Noel A, De Pauw E. Towards lipidomics of lowabundant species for exploring tumor heterogeneity guided by high-resolution mass spectrometry imaging. Int J Mol Sci. 2013; 14: 24560-24580.

12. Ma Y, Zhang P, Yang Y, Wang F, Qin H. Metabolomics in the fields of oncology: a review of recent research. Mol Biol Rep. 2012; 39: 7505-7511.

13. Dekker LJ, Burgers PC, Guzel C, Luider TM. FTMS and TOF/TOF mass spectrometry in concert: identifying 
peptides with high reliability using matrix prespotted MALDI target plates. J Chromatogr B Analyt Technol Biomed Life Sci. 2007; 847: 62-64.

14. Jones JJ, Borgmann S, Wilkins CL, O'Brien RM. Characterizing the phospholipid profiles in mammalian tissues by MALDI FTMS. Anal Chem. 2006; 78: 3062-3071.

15. Griffin JL, Lehtimäki KK, Valonen $\mathrm{PK}$, Gröhn $\mathrm{OH}$, Kettunen MI, Ylä-Herttuala S, Pitkänen A, Nicholson JK, Kauppinen RA. Assignment of $1 \mathrm{H}$ nuclear magnetic resonance visible polyunsaturated fatty acids in BT4C gliomas undergoing ganciclovir-thymidine kinase gene therapy-induced programmed cell death. Cancer Res. 2003; 63: 3195-3201.

16. Singer S, Millis K, Souza K, Fletcher C. Correlation of lipid content and composition with liposarcoma histology and grade. Ann Surg Oncol. 1997; 4: 557-563.

17. Zhou QY, Wang YL, Li X, Shen XY, Li KJ, Zheng J, Yu YQ. Metabolomics investigation of cutaneous $\mathrm{T}$ cell lymphoma based on UHPLC-QTOF/MS. Asian Pac J Cancer Prev. 2013; 15: 5417-5421.

18. Cimino J, Calligaris D, Far J, Debois D, Blacher S, Sounni NE, Noel A, De Pauw E. Towards lipidomics of lowabundant species for exploring tumor heterogeneity guided by high-resolution mass spectrometry imaging. Int J Mol Sci. 2013; 14: 24560-24580.

19. Schöne $C$, Höfler $H$, Walch A. MALDI imaging mass spectrometry in cancer research: combining proteomic profiling and histological evaluation. Clin Biochem. 2013; 46: 539-545.

20. McDonnell LA, Corthals GL, Willems SM, van Remoortere A, van Zeijl RJ, Deelder AM. Peptide and protein imaging mass spectrometry in cancer research. J Proteomics. 2010; 73: 1921-1944.

21. Dobrzyńska I, Szachowicz-Petelska B, Darewicz B, Figaszewski ZA. Characterization of human bladder cell membrane during cancer transformation. J Membr Biol. 2015; 248: 301-307.

22. Kim HY, Lee KM, Kim SH, Kwon YJ, Chun YJ, Choi HK. Comparative metabolic and lipidomic profiling of human breast cancer cells with different metastatic potentials. Oncotarget. 2016; 7: 67111-67128. doi: 10.18632/ oncotarget.11560.

23. Taniguchi M, Okazaki T. The role of sphingomyelin and sphingomyelin synthases in cell death, proliferation and migration - from cell and animal models to human disorders. Biochim Biophys Acta. 2014; 1841: 692-703.

24. Ségui B, Andrieu-Abadie N, Jaffrézou JP, Benoist H, Levade T. Sphingolipids as modulators of cancer cell death: potential therapeutic targets. Biochim Biophys Acta. 2006; 1758: 2104-2120.

25. Guo S, Wang Y, Zhou D, Li Z. Electric field-assisted matrix coating method enhances the detection of small molecule metabolites for mass spectrometry imaging. Anal Chem. 2015; 87: 5860-5865. 